\title{
REMOÇÃO DE METAIS PESADOS ATRAVÉS DA REMEDIAÇÃO ÁCIDA E ALCALINA DE CATALISADORES DESATIVADOS DE FCC
}

\author{
R. F. LEONEL ${ }^{1}$, R. B. G. VALT ${ }^{2}$, L. S. SANCHES ${ }^{3}$, M. J. J. S. PONTE ${ }^{4}$, H. A. PONTE ${ }^{5}$ \\ ${ }^{1}$ Universidade Federal do Paraná, Programa de Pós-Graduação em Ciência e Engenharia de Materiais \\ ${ }^{2}$ Universidade Federal do Paraná, Pesquisadora Visitante PRH24 \\ ${ }^{3}$ Universidade Federal do Paraná, Programa de Pós-Graduação em Engenharia de Mecânica \\ ${ }^{4}$ Universidade Federal do Paraná, Departamento de Engenharia Mecânica \\ ${ }^{5}$ Universidade Federal do Paraná, Departamento de Engenharia Química \\ E-mail para contato: raquel.folmann@gmail.com
}

\begin{abstract}
RESUMO - O crescente desenvolvimento do setor petrolífero e a consequente geração de resíduos advindos dessas atividades tem demandado inúmeras pesquisas em diversos setores tecnológicos, visando uma eficiência ambiental em sua destinação. O processo de remediação eletrocinética vem ao encontro desta necessidade, aplicando potencial elétrico ao sistema para a mobilização e remoção dos metais aderidos ao material em tratamento. No presente trabalho, o catalisador desativado de FCC foi remediado com o emprego de soluções de citrato de sódio e ácido sulfúrico como eletrólitos, junto a aplicação de potencial elétrico de $11 \mathrm{~V}$ durante $48 \mathrm{~h}$. O material tratado foi analisado através da técnica de FRX para a determinação do teor de níquel e vanádio antes e após o tratamento. A remediação ácida removeu $24 \%$ de V, enquanto a alcalina removeu $29 \%$ de V. Para as duas condições a remoção de níquel foi próxima a $2 \%$. Vislumbra-se assim o potencial de aplicação da técnica para a regeneração deste tipo de material.
\end{abstract}

\section{INTRODUÇÃO}

A crescente demanda por combustíveis de alta qualidade vem impulsionando as pesquisas na área petroquímica. Uma melhora no rendimento em gasolina foi alcançada pela substituição do craqueamento térmico pelo craqueamento catalítico. Os catalisadores mais utilizados no processo FCC (Craqueamento Catalítico em leito Fluidizado) são baseados em aluminossilicatos tridimensionais de estrutura porosa, chamados zeólitas. As zeólitas exibem propriedades catalíticas singulares, sendo chamadas nanorreatores. De acordo com sua estrutura cristalina podem ser criados poros com até 12,5 Angstrons, dentro dos quais acontecem as reações de cracking (Guisnet e Ribeiro, 2004).

A zeólita Y, ilustrada na Figura 1, com estrutura análoga ao mineral faujasita, é composta por tetraedros $\left(\mathrm{TO}_{4}\right.$, onde $\mathrm{T}$ pode ser Silício ou Alumínio) formando um octaedro truncado chamado sodalita ou caixa beta, com uma cavidade central. A associação de várias unidades sodalita através de prismas hexagonais gera a supercavidade alfa. A rede de poros na zeólita proporciona elevada área 
superficial e grande capacidade de adsorção (Montanari et al., 2011).

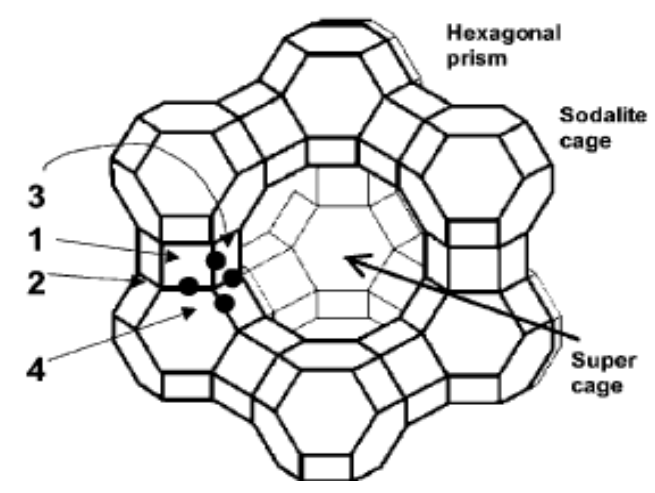

Figura 1 - Estrutura da Zeólita Y, de 1 a 4 as posições cristalográficas distintas do oxigênio.

As severas condições de operação da unidade FCC, como altas temperaturas e frações pesadas de petróleo com a presença de contaminantes como ferro, níquel e vanádio, levam à diminuição da atividade catalítica da zeólita. A cada ciclo de carga craqueada o catalisador passa pela etapa de regeneração para queima dos depósitos de coque (Cerqueira et al., 2008).

O catalisador regenerado retorna ao processo, contudo sua eficiência é reduzida e se faz necessária a adição de catalisador novo. O catalisador vai sofrendo gradativamente uma degradação dos sítios ativos em catálise, o que caracteriza um limite de vida útil ou um "prazo de validade", conhecido como número de campanhas do catalisador.

Porfirinas metálicas presentes no petróleo cru se decompõem durante o craqueamento e os metais se depositam na superfície do catalisador. Durante a regeneração o vanádio migra para a estrutura da zeólita e reage com o alumínio destruindo o sítio ativo e levando ao colapso parcial da estrutura. O níquel depositado no catalisador leva ao craqueamento não seletivo, contribuindo para a desidrogenação e formação de maiores quantidades de coque. Essas interações reduzem a área superficial da zeólita e diminuem sua atividade catalítica (Ravichander et al., 2009). Assim, grandes quantidades de catalisador de equilíbrio, ou desativados, são gerados pelas refinarias, que ao final de sua vida útil são enviados para aterros classe I ou para coprocessamento em indústrias cimenteiras.

A remediação eletrocinética surge como alternativa para tratamento de materiais contaminados com espécies iônicas que possam ser mobilizadas através da condução elétrica. Aplica-se um gradiente de potencial elétrico da ordem de alguns volts por centímetro entre dois eletrodos e o material a ser tratado entre eles (Yeung, 2011). A variação de alguns parâmetros na remediação eletrocinética, como tipo de solução, $\mathrm{pH}$, vazão do eletrólito e corrente, permite otimizar a retirada dos metais (Valt, 2012).

Uma reação eletroquímica é um processo químico heterogêneo, onde há uma interface entre o sólido a ser tratado e o eletrólito que o envolve e favorece a transferência de cargas entre eletrodos. Os eletrodos são usualmente bons condutores elétricos e normalmente são metais sólidos, embora 
uma grande variedade de outros materiais também possa ser utilizada, incluindo cerâmicas e polímeros condutores. O eletrólito é usualmente um condutor iônico, como uma solução aquosa de um sal, ácido ou base.

O circuito elétrico em uma célula eletroquímica pode ser convenientemente dividido em duas partes. No circuito elétrico externo, a corrente flui em uma direção, do ânodo para o cátodo, como um fluxo de elétrons. Dentro da célula, a corrente flui eletronicamente dentro da estrutura dos eletrodos e ionicamente no eletrólito, entre os eletrodos. No eletrólito, a corrente flui por migração de íons, em que os ânions movem-se em direção ao ânodo e os cátions movem-se em direção ao catodo (Schultz, 2003).

É importante visualizar que em uma célula eletroquímica existe um balanço de carga de tal modo que a quantidade de carga envolvida no processo de redução no cátodo tem que ser a mesma que a envolvida no processo de oxidação no ânodo (Ponte, 1999).

No anodo, a oxidação da água gera uma frente ácida $(\mathrm{H}+)$ contribuindo para ionização de algumas espécies na solução (facilitando sua remoção) enquanto no catodo ocorre uma redução, produzindo uma frente básica (OH-) a qual faz com que algumas espécies precipitem (dificultando sua remoção), conforme as Reações 1 e 2 abaixo:

$$
\begin{gathered}
2 \mathrm{H}_{2} \mathrm{O}-4 \dot{e} \rightarrow \mathrm{O}_{2} \uparrow+4 \mathrm{H}^{+} \text {(anodo) } \\
4 \mathrm{H}_{2} \mathrm{O}+4 \dot{e} \rightarrow 2 \mathrm{H}_{2} \uparrow+4 \mathrm{OH}^{-} \text {(catodo) }
\end{gathered}
$$

Deste modo, este estudo tem como objetivo remover os metais aderidos ao catalisador desativado utilizando o tratamento de remediação eletrocinética em meio ácido e em meio alcalino.

\section{MATERIAIS E MÉTODOS}

Para o desenvolvimento deste trabalho foram utilizados catalisadores desativados de petróleo tratados com aplicação da técnica de remediação eletrocinética e posterior análise por microscopia e composição química.

\subsection{Remediação Eletrocinética}

A remediação eletrocinética utiliza um reator cilíndrico, segundo modelo primeiramente proposto por Yeung et al. (1997). O reator é preenchido com catalisador desativado e este é imerso em um eletrólito. Nas extremidades do reator são posicionados eletrodos para permitir a aplicação de potencial. Como anodo utilizou-se uma chapa de Ti/Ir-Ru e como catodo utilizou-se uma chapa de Pb. O eletrólito é continuamente renovado através de uma bomba peristáltica a vazão fixa. $\mathrm{O}$ esquema de instalação experimental pode ser visto na Figura 2. 


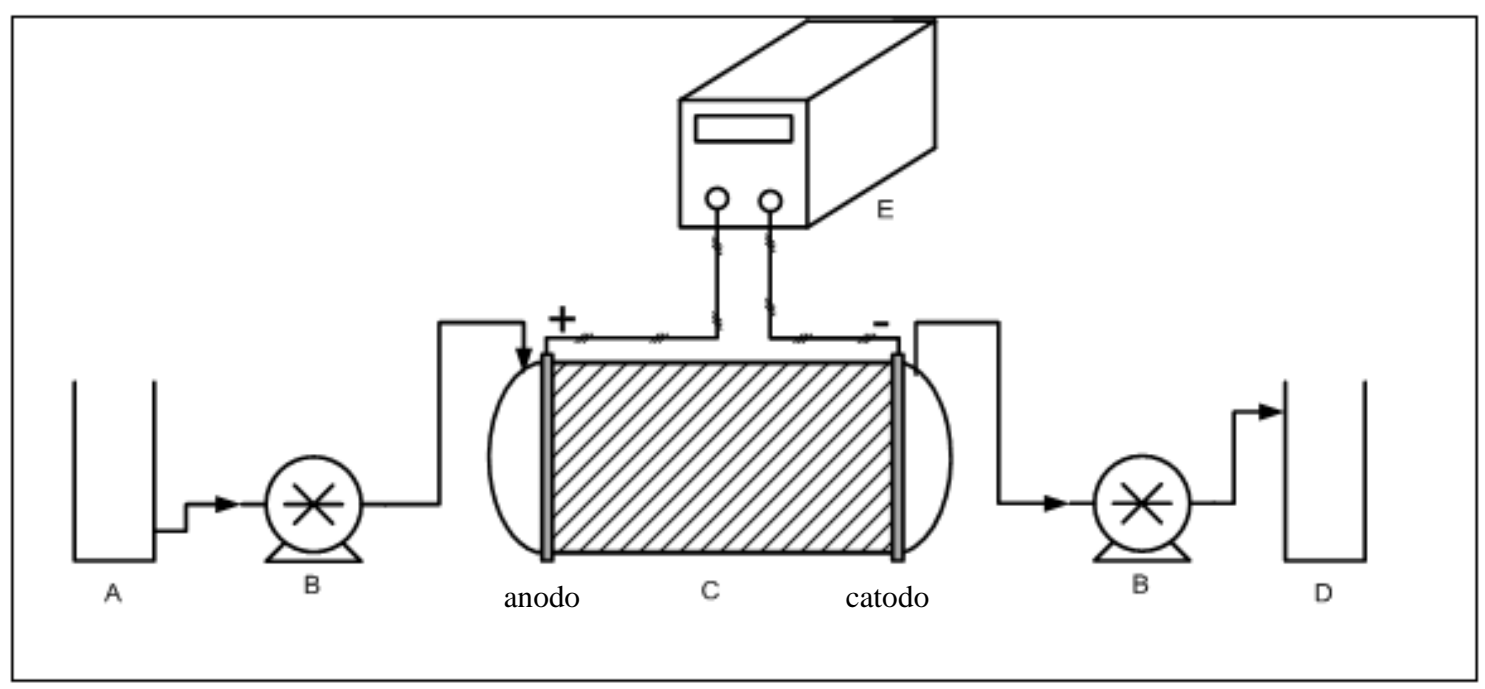

Figura 2 - Esquema Experimental da instalação de Remediação Eletrocinética (A: reservatório de eletrólito novo; B: bomba peristáltica; C: reator eletrocinético; D: reservatório de eletrólito contaminado; E: fonte de potencial)

Baseado em estudos anteriores realizados por Baptista (2005) e Creplive (2008), a melhor condição experimental para remoção de vanádio foi com lavagem ácida através de solução de $\mathrm{H}_{2} \mathrm{SO}_{4}$ de concentração 1,0 M. Assim, esta condição foi aplicada neste estudo. O catalisador permaneceu em repouso com eletrólito durante 24 horas. Em seguida, aplicou-se potencial elétrico de $11 \mathrm{~V}$ associado a bombeamento peristáltico de $100 \mathrm{~mL} /$ hora do eletrólito por 48 horas. Decorrido este tempo foi bombeada água destilada para remoção do eletrólito e metais superficiais e procedeu-se à secagem do material em estufa a $45^{\circ} \mathrm{C}$ por $48 \mathrm{~h}$.

O mesmo procedimento foi aplicado utilizando-se uma solução $0,5 \mathrm{M}$ de citrato de sódio como eletrólito. $\mathrm{O}$ meio eletrolítico contendo o íon citrato foi selecionado devido ao fato deste ânion ter facilidade em complexar íons vanádio, tanto em meio alcalino quanto em meio ácido. O complexo de citrato mais íons apresenta estruturas distintas em $\mathrm{pH}=0$ e $\mathrm{pH}=8$, porém com mesmo poder de complexação (Cruywagen, et al., 1995 e Sanches, et al., 2003). Neste estudo foi utilizado pH = 8 .

\subsection{Microscopia Eletrônica de Varredura}

As análises de Microscopia Eletrônica de Varredura (MEV) foram realizadas no Centro de Microscopia Eletrônica (CME) na Universidade Federal do Paraná, através do equipamento Jeol® modelo JSM - 6360LV Scanning Electron Microscope.

Estas análises permitiram avaliar o aspecto morfológico do catalisador podendo indicar o grau de destruição ou modificação na estrutura dos grãos devido ao processo de remediação aplicado. 


\subsection{Análise de Metais}

Após o tratamento por remediação eletrocinética, os teores de metais foram determinados por fluorescência de raios-X. Para os testes de fluorescência de raios-X procedeu-se à preparação de pastilhas dos catalisadores. Fez-se a moagem de uma pequena quantidade do catalisador em moinho de Carbeto de Tungstênio. Em seguida pesou-se $7 \mathrm{~g}$ do catalisador moído (com erro máximo de \pm $0,0001 \mathrm{~g})$ e adicionou-se 1,4 g de aglomerante. Homogeneizou-se a mistura de catalisador e aglomerante e prensou-se a mistura em uma prensa PFAFF com pressão de até $40 \mathrm{tf} / \mathrm{cm}^{2}$. A pastilha prensada foi então levada ao equipamento de fluorescência de raios-X (aparelho marca Philips, modelo PW 2400) para realizar a leitura da concentração de todos os elementos presentes nas amostras.

\section{RESULTADOS}

\subsection{Microscopia Eletrônica de Varredura}

As imagens obtidas na microscopia eletrônica de varredura são apresentadas na Figura 3, para o catalisador desativado e remediado com ácido sulfúrico e citrato de sódio.

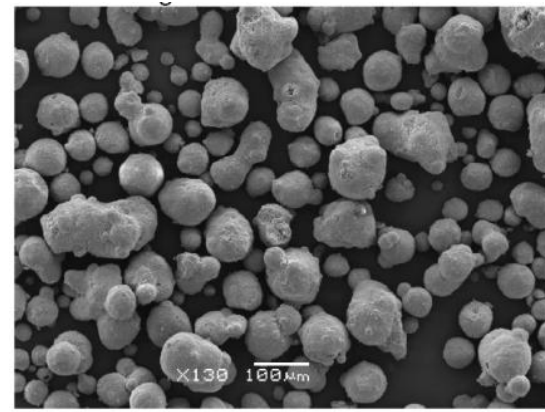

(A)

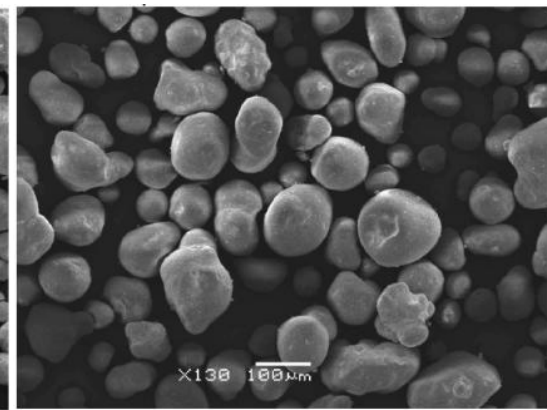

(B)

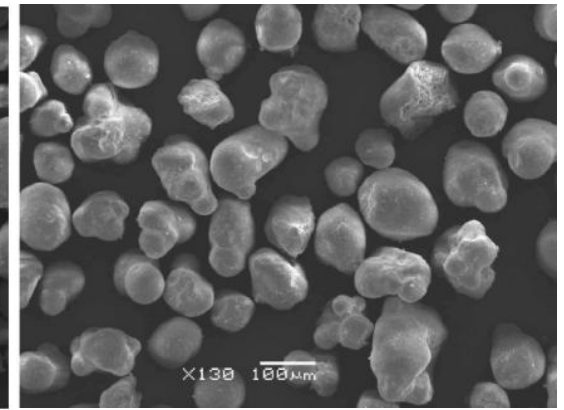

(C)

Figura 3 - Microscopia Eletrônica de Varredura: (A) Antes da remediação com aumento de 130X, (B) após a remediação com ácido sulfúrico com aumento de 130X, (C) Após a remediação com citrato de sódio com aumento de 130X.

Pode-se observar pelas imagens que o processo de remediação eletrocinética não afetou a morfologia do material, uma vez que não há diferenças significativas na superfície das partículas entre o catalisador contaminado e remediado.

\subsection{Análise de Metais}

A Tabela 1 apresenta a composição do material em estudo, sendo avaliado o material antes da remediação (desativado) e após a remediação com os diferentes eletrólitos (ácido sulfúrico e citrato de sódio). Em destaque o percentual de remoção de cada tratamento. 
Tabela 1 - Composição química do catalisador desativado

\begin{tabular}{|c|c|c|c|c|c|}
\hline Substância & Desativado & $\begin{array}{c}\text { Remediado } \\
\text { com ácido } \\
\text { sulfúrico }\end{array}$ & $\begin{array}{c}\text { \% removido } \\
\text { com ácido } \\
\text { sulfúrico }\end{array}$ & $\begin{array}{c}\text { Remediado } \\
\text { com citrato } \\
\text { de sódio }\end{array}$ & $\begin{array}{c}\text { \% removido } \\
\text { com citrato } \\
\text { de sódio }\end{array}$ \\
\hline $\mathrm{Al}_{2} \mathrm{O}_{3}(\%)$ & 39,3 & 37,7 & $\mathbf{4 , 0 7}$ & 38,9 & $\mathbf{1 , 0 2}$ \\
\hline $\mathrm{SiO}_{2}(\%)$ & 50,6 & 50,0 & $\mathbf{1 , 1 9}$ & 47,7 & $\mathbf{5 , 7 3}$ \\
\hline $\mathrm{Na}(\%)$ & 0,39 & 0,22 & $\mathbf{4 3 , 5 9}$ & 0,80 & $\mathbf{- 1 0 5 , 1 3}$ \\
\hline $\mathrm{P}_{2} \mathrm{O}_{5}(\%)$ & 1,160 & 0,400 & $\mathbf{6 5 , 5 2}$ & 1,085 & $\mathbf{6 , 4 7}$ \\
\hline $\mathrm{Fe}(\%)$ & 0,77 & 0,49 & $\mathbf{3 6 , 3 6}$ & 0,56 & $\mathbf{2 7 , 2 7}$ \\
\hline $\mathrm{Ni}(\%)$ & 0,284 & 0,280 & $\mathbf{1 , 4 4}$ & 0,278 & $\mathbf{2 , 3 2}$ \\
\hline $\mathrm{V}(\%)$ & 0,200 & 0,152 & $\mathbf{2 4 , 0 9}$ & 0,142 & $\mathbf{2 9 , 1 9}$ \\
\hline
\end{tabular}

Nota-se que a composição majoritária do catalisador é dos óxidos sílica e alumina, como esperado, por se tratar de uma zeólita dispersa numa matriz de sílica e alumina. O sódio, encontrado em teor residual no catalisador desativado, pode ser proveniente de permuta incompleta quando da síntese da zeólita e que foi posteriormente trocado com hidrogênio, ou proveniente do petróleo. No catalisador remediado com citrato de sódio houve um aumento da quantidade de sódio após o experimento, provavelmente devido a um residual de eletrólito no material.

Como contaminantes foram encontrados os óxidos de fósforo e os metais presentes como elementos traço do petróleo, ferro, níquel e vanádio, que se esperava retirar do catalisador através da remediação. A quantidade de níquel removida nos dois tratamentos foi de aproximadamente $2 \%$. No caso do vanádio, o tratamento com citrato de sódio teve uma remoção de $29,19 \%$, levemente superior ao do tratamento com ácido sulfúrico que removeu 24,09\%.

Cabe salientar que as diferenças de teor de alumínio e silício após a remediação não alteraram a estrutura da zeólita mas podem alterar a estabilidade térmica do material, fato que está será avaliado na continuidade da pesquisa. Além disso, pesquisas futuras deverão ser realizadas no sentido de reutilizar este catalisador remediado e recuperar os metais removidos e que encontram-se no efluente do processo.

\section{CONCLUSÃO}

Através da metodologia empregada, foram tratadas por remediação eletrocinética amostras de catalisador desativado de FCC variando a composição dos eletrólitos.

Como conclusões iniciais deste estudo, tem-se que com relação à remoção do metal vanádio, a remediação com ácido sulfúrico e citrato de sódio proporcionaram resultados similares. Para os dois casos, o teor do metal níquel sofreu pouca alteração. 
A remediação também resultou na remoção de pequenas quantidades de alumínio e sílica (dentro da faixa de erro da técnica de FRX), componentes base da zeólita, mas que aparentemente não comprometeram a estrutura do material. As imagens de MEV permitiram visualizar a manutenção da morfologia do material. Vislumbra-se assim o potencial de aplicação da técnica para a regeneração deste tipo de material.

\section{REFERÊNCIAS}

BAPTISTA, A. Avaliação do potencial de recuperação de metais de catalisadores equilibrados através da técnica de remediação eletrocinética, 2005. Tese. Universidade Federal do Paraná.

CERQUEIRA, H. S.; CAEIRO, G.; COSTA, L. Deactivation of FCC catalysts. Journal of Molecular Catalysis, v. 292, p. 1-13, 2008.

CREPLIVE, M. R. Remoção de vanádio a partir de catalisadores termodinamicamente estáveis, 2008. Universidade Federal do Paraná.

CRUYWAGEN, J. J.; ROHWER, E. A. \& WESSELS, G. F. S. Molybdenum (VI) complex formation - Equilibria and thermodynamic quantities for the reactions with citrate. Polyedron, v. 14: 3481, 1995.

GUISNET, M.; RIBEIRO, F. R. Zeólitos - Um nanomundo a serviço da catálise. Lisboa: Fundação Calouste Gulbenkian, 2004.

MONTANARI, T.; FINOCCHIO, E.; BUSCA, G. Infrared Spectroscopy of Heterogeneous catalyst: Acidity and Accessibility of Acid Sites of Faujasite-Type Solid Acids. Journal of Physics and Chemistry, v. 115, n. 4: 937-943, 2011.

PONTE, H.A. Fundamentos da Eletrodeposição: Introdução. Departamento de Tecnologia Química, Universidade Federal do Paraná, 1999.

RAVICHANDER, N.; CHIRANJEEVI, T.; GOKAK, D. T.; VOOLAPALLI, R. K.; CHOUDARY, N. V. FCC catalyst and additive evaluation-A case study. Catalysis Today, v. 141, p. 115-119, 2009.

SANCHES, L.; DOMINGUES, S.; CARUBELLI, A. \& MASCARO, L. Electrodeposition of NiMo and Fe-Mo Alloys from Sulfate-Citrate Acid Solutions. Journal Brazilian Chemical Society, v. 14, p. 55, 2003. 
SCHULTZ, D.R.. Recuperação de Metais Pesados (Pb, Cu e Ni) de Efluentes Industriais Utilizando Reator Eletroquímico de Leito Particulado. Dissertação, 2003. Universidade Federal do Paraná.

VALT, R. B. G. Regeneração eletrocinética, reciclagem e reuso de catalisadores desativados de FCC na adsorção de dióxido de carbono e craqueamento de petróleo, 2012. Universidade Federal do Paraná.

YEUNG, A. T. Milestone developments, myths, and future directions of electrokinetic remediation. Separation and Purification Technology, v. 79, n. 2, p. 124-132, 2011. Elsevier B.V.

YEUNG, A. T.; HSU, C.; MENON, R. M. Physicochemical soil-contaminant interactions during electrokinetic extraction. Journal of Hazardous Materials, v. 55, p. 221-237, 1997. 